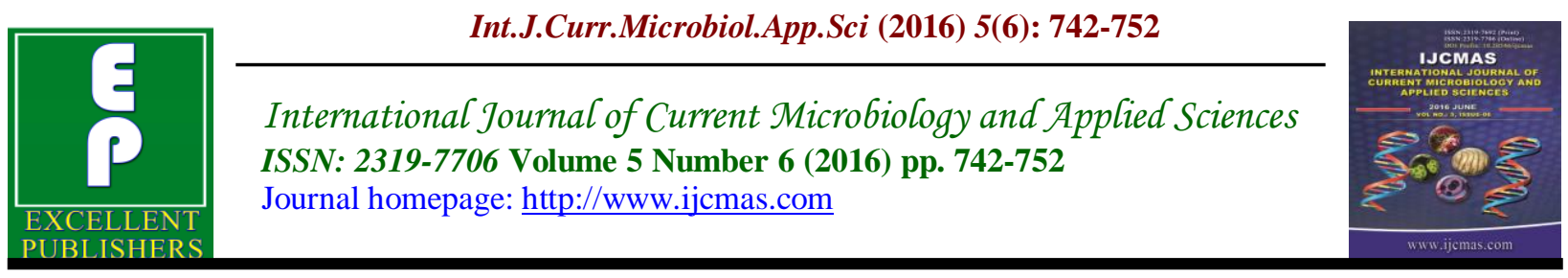

Original Research Article

http://dx.doi.org/10.20546/ijcmas.2016.506.080

\title{
UV and Solar Degradation of Ofloxacin Antibiotic
}

\author{
Gayatri Devi Singh, K.C. Gupta ${ }^{1 *}$ and Archana Shrivastawa ${ }^{2}$ \\ ${ }^{1}$ Department of Microbiology, VRG Girls College, Morar Gwalior, (M.P.) India \\ ${ }^{2}$ Department of Microbiology, College of Life Science, Cancer Hospital and Research Institute \\ Gwalior, (M.P.) India \\ *Corresponding author
}

\section{A B S T R A C T}

Keywords

Photodegradation, photolysis, ofloxacin, UV radiations, fluoroquinolones.

\section{Article Info}

Accepted:

25 May 2016

Available Online:

10 June 2016
The ofloxacin is a synthetic antibiotic, which belongs to the second generation of fluoroquinolones group. It acts against the Gram positive and Gram negative bacteria by inhibiting the DNA gyrase activity. The different concentrations of antibiotic solution ranging from 50 to $500 \mathrm{ppm}$, was exposed to the sun light and UV radiation. The solar exposure duration for the degradation, was 12 to $108 \mathrm{hrs}$. and UV exposure duration for the degradation, was 1 to $7 \mathrm{hrs}$. For the present study the UV radiation $(15 \mathrm{~W}$ and $30 \mathrm{~W})$ tubes, which were attached in the Laminar air flow, were used. The degradation capacity was measured by the zone of inhibition appeared after treatment. The maximum degradation of ofloxacin was recorded after $6 \mathrm{hrs}$. of exposure of UV (30W). The higher solar degradation was also recorded at $108 \mathrm{hrs}$. exposure duration, but degradation efficiency was lower than UV exposure. For the control of pollution in the environment caused by ofloxacin antibiotic residues, was significantly controlled by the treatment of UV and the photolysis.

\section{Introduction}

Ofloxacin is a synthetic chemotherapeutic antibiotic having activity against gram negative as well as gram positive bacteria through inhibition of their DNA gyrase (Hubicka et al., 2013; Sato et. al., 1982). This antibiotic belongs to second-generation fluoroquinolone. Its IUPAC name is 9fluro-2, 3-dihydro-3-methyl-10-(4-methyl-1piperizinyl)-7-oxo-7H-pyrido[1,2,3-de]-1,4benzoxaine-6-carboxylic acid. It is widely used in the treatment of respiratory and urinary tract infections (Ichihara et. al., 1984).The ofloxacin shows its potential effects on agricultural soil micro flora and is recently determined as antibiotic contaminated bio-solids in agricultural fields. However, it was observed that this was less affective to the soil microbial community function in comparison to the other antibiotics (Liu et al., 2012). Several antibiotics present in soil are responsible for causing antibiosis, which is a natural defense mechanism with numerous soil microorganisms, producing antibiotics via their secondary metabolism (Thomashow et al., 1997). Ferguson et al. (1988) observed the UV degradation of ciprofloxacin. Tiefenbacher et al., (1994) investigated that 
the photodegradation of fluoroquinolones, such as ciprofloxacin, ofloxacin and fleroxacin by ultraviolet irradiation and natural room light in liquid medium. Fluoroquinolone carboxylic acid was photodegradable in aqueous medium (Burhenne et al., 1997a, b). Vasquez et al., (2013) studied the degradation of antibiotic ofloxacin in waste water with the help of UV radiations in the presence of $\mathrm{TiO}_{2}$. Hubicka et al., (2013) studied the degradation of moxifloxacin, ciprofloxacin, norfloxacin and ofloxacin in aquatic medium by ultra-violet exposure and noticed that these antibiotics were degraded in several simpler products. Santos et al., (2015) investigated the photodegradation of norfloxacin antibiotic with the help of direct UV exposure, Fenton's oxidation process and photolysis in the presence of $\mathrm{H}_{2} \mathrm{O}_{2}$ in waste water effluent.

Liu et al., (2015) studied the photodegradation of antibiotics the florfenicol and thiamphenicol with the help of the exposure of UV irradiations and addition with $\mathrm{H}_{2} \mathrm{O}_{2}$ and $\mathrm{Fe}$ (II) ions. Peres et al., (2015) reported the degradation of ofloxacin antibiotic in liquid medium with the help of UV radiation exposure in the presence of $\mathrm{TiO}_{2}$ as catalyst and the $\mathrm{H}_{2} \mathrm{O}_{2}$. Philips et al., (1990) reported that after photodegradation, the antibacterial activity of ciprofloxacin was decreased. Sturini et al., (2015) studied the solar photodegradation of four fluoroquinolones, the ciprofloxacin, danofloxacin, enrofloxacin and marbofloxacin and one penicillin, the ampicillin in treated waste water effluents. Ge et al., (2015) recorded the direct solar light degradation of six fluoroquinolones, the ciprofloxacin, sarafloxacin, difloxacin, enrofloxacin, danofloxacin and levofloxacin in liquid medium. Tay et al., (2015) recorded the degradation of ofloxacin antibiotic with the help of ozonation process in the aquatic medium. They also recorded that in this degradation process many by-products were formed out of which some were harmful to humans. They further studied that the ozone and hydroxyl radicals were effected the ofloxacin degradation.In the present study authors have focussed the photo- and UV degradation of ofloxacin and determined the degradation by zone of inhibition.

\section{Materials and Methods}

\section{Chemicals and Media}

Ofloxacin 200mg (manufactured by Macleods pharmaceuticals Ltd. Solan, Himachal Pradesh, India) was used. The Muller-Hinton agar media (High media) was used for the determination of the zone of inhibition.

\section{Experimental Setup}

\section{Effects of Sun Light on Antibiotics}

Different concentrations of ofloxacin antibiotic solutions (50, 100, 200, 300, 400 and $500 \mathrm{ppm}$ ) were prepared and poured in the petriplates for experiments. These plates were exposed to sun light during day time in the month of March in the Gwalior region (Madhya Pradesh, India) the temperature was $30^{\circ} \mathrm{C}$, the sun light exposure was period ranging from 12-108 hrs. was observed. The antibiotic discs were prepared by dipping in the different concentrations of antibiotic, which were exposed to the sun light. The controls discs dipped in untreated antibiotic solutions were also prepared.

The bacterial culture was prepared in the petriplates containing the Muller-Hinton agar media The treated and control discs were placed in these petriplates. The petriplates, containing treated and control discs, were exposed to the environment of VRG PG College, Gwalior (M.P., India) for 
bacterial culture for five minutes. After exposure these plates were incubated at $37^{\circ} \mathrm{C}$ for $48 \mathrm{hrs}$. The inhibition zones appeared in the petriplates was measured in millimeters (Jasim et al., 2010; Chen et al., 2011; Hernandez et al., 2012).

\section{Effects of UV Radiation on Antibiotics}

Different concentrations of ofloxacin antibiotic solutions (50, 100, 200, 300, 400 and $500 \mathrm{ppm}$ ) were prepared and poured in the petriplates for experiments. These plates were exposed to UV radiation in laboratory at $30^{\circ} \mathrm{C}$ temperature for the period ranging from 1-7 hrs. The UV-lamps (Philips, 15W and $30 \mathrm{~W}$ ) were used as source for UV radiation. The antibiotic discs were prepared by dipping in the different concentrations of antibiotic, which were exposed to the UV radiation. The controls discs containing untreated antibiotic solutions were also prepared.

The petriplates containing the Muller-Hinton agar media were also prepared for the bacterial culture. The treated and control discs were placed in these petriplates. These petriplates (containing treated and control discs) were exposed to the environment of
VRG PG College, Gwalior (M.P., India) for bacterial culture for five minutes. Then these plates were incubated at $37^{\circ} \mathrm{C}$ for $48 \mathrm{hrs}$. The inhibition zones appeared in the petriplates was measured in millimeters (Jasim et al., 2010; Chen et al., 2011; Hernandez et al., 2012).

\section{Results and Discussion}

The experiment was set up to determine the UV degradation of ofloxacin by two UV intensities. The authors have recorded the higher degradation after 6hrs. of exposure of the ofloxacin at $15 \mathrm{~W}$ UV tube. After $30 \mathrm{~W}$ of UV exposure of also showed the higher degradation at 6hrs.of exposure (table 1 and 2, fig. 3, 4, 5, 6, 7 and 8). The degradation efficiency of ofloxacin antibiotic, after exposure of 15 and $30 \mathrm{~W} \mathrm{UV}$ radiation, increased continuously till 6 hours of exposure. The degradation rate became stable after $6 \mathrm{hrs}$. of radiation. The ofloxacin showed higher degradation after 108 hours of solar exposure at concentration 50, 100, 200, 300, 400 and 500ppm (table 3 and fig. 9 ). Degradation efficiency of solar exposure was maximum at 500ppm (figure 2).

Fig.1 Chemical structure of ofloxacin modified from Application submitted by International Council of Ophthalmology.

Chemical formula: C18H20FN3O4 (Rege et. al., 2011), Molecular weight: 361.37

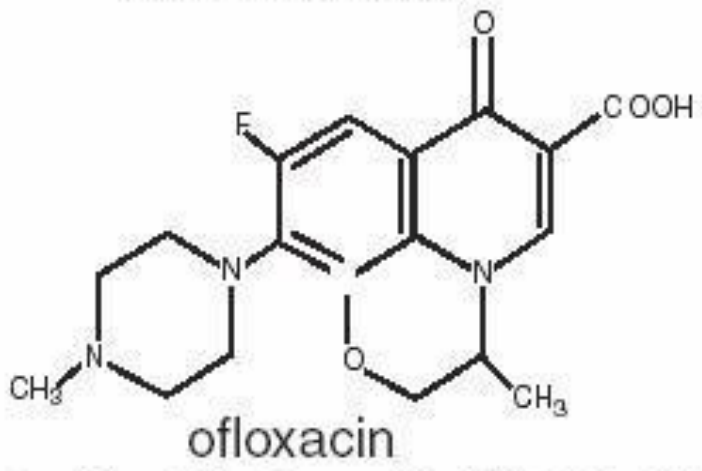


Fig.2 Ofloxacin degradation (a.) Zone of inhibition of 300ppm solution of ofloxacin without treatment (b.) and (c.)Zone of inhibition of 300ppm solution of ofloxacin after UV and solar treatment

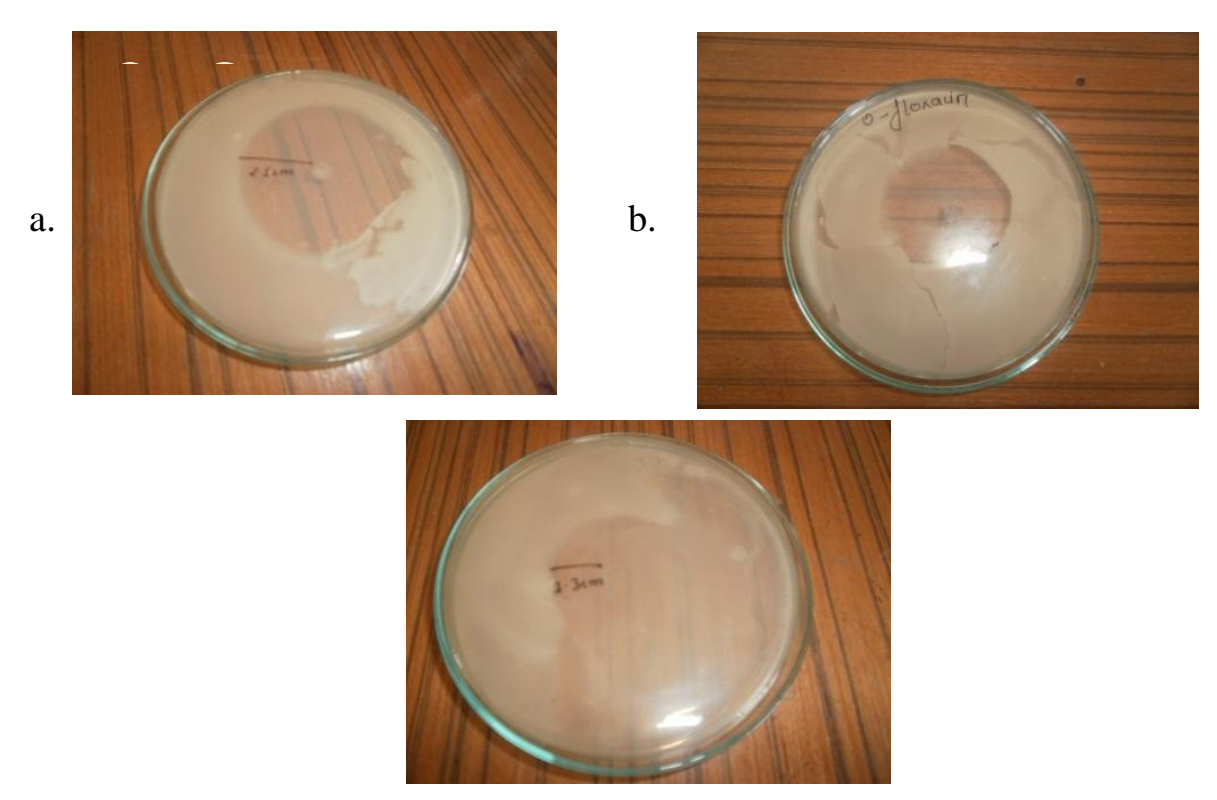

c.

Table.1 Zone of inhibition (in mm) of the Ofloxacin with UV (15W) treatment

\begin{tabular}{|c|c|c|c|c|c|c|}
\hline $\begin{array}{l}\text { Con. } \longrightarrow \\
\text { Exposume } \\
\text { Time }\end{array}$ & 50ppm & 100ppm & 200ppm & 300ppm & 400ppm & 500ppm \\
\hline Non treated & 15 & 18 & 19 & 21 & 23 & 25 \\
\hline 1hrs & 13 & 16 & 16 & 17 & 20 & 19 \\
\hline $2 \mathrm{hrs}$ & 12 & 13 & 14 & 13 & 17 & 13 \\
\hline $3 \mathrm{hrs}$ & 9 & 10 & 12 & 11 & 15 & 11 \\
\hline 4hrs & 7 & 9 & 8 & 6 & 11 & 9 \\
\hline 5hrs & 5 & 7 & 5 & 4 & 8 & 6 \\
\hline$\overline{6 h r s}$ & 3 & 3 & 4 & 3 & 5 & 4 \\
\hline $7 \mathrm{hrs}$ & 3 & 3 & 4 & 3 & 5 & 4 \\
\hline
\end{tabular}


Table.2 Zone of inhibition (in mm) of the Ofloxacin with UV (30W) treatment

\begin{tabular}{|l|l|l|l|l|l|l|}
\hline \multicolumn{1}{|c|}{$\begin{array}{l}\text { Exposur } \\
\text { Time }\end{array}$} & $\mathbf{5 0 p p m}$ & $\mathbf{1 0 0 p p m}$ & $\mathbf{2 0 0 p p m}$ & $\mathbf{3 0 0 p p m}$ & $\mathbf{4 0 0 p p m}$ & $\mathbf{5 0 0 p p m}$ \\
\hline Non treated & 15 & 18 & 19 & 21 & 23 & 25 \\
\hline Thrs & 12 & 15 & 14 & 15 & 19 & 18 \\
\hline 2hrs & 11 & 12 & 12 & 12 & 16 & 12 \\
\hline 3hrs & 8 & 9 & 10 & 10 & 14 & 10 \\
\hline 4hrs & 6 & 8 & 7 & 5 & 10 & 8 \\
\hline Shrs & 4 & 6 & 6 & 3 & 7 & 5 \\
\hline 6hrs & 2 & 2 & 3 & 2 & 4 & 3 \\
\hline 7hrs & 2 & 2 & 3 & 2 & 4 & 3
\end{tabular}

Table.3 Zone of inhibition (in $\mathrm{mm}$ ) of the ofloxacin with sun light treatment

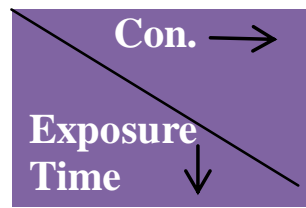

\begin{tabular}{|l|l|l|l|l|l|}
\hline $\mathbf{5 0 p p m}$ & $\mathbf{1 0 0 p p m}$ & $\mathbf{2 0 0 p p m}$ & $\mathbf{3 0 0 p p m}$ & $\mathbf{4 0 0 p p m}$ & $\mathbf{5 0 0 p p m}$ \\
\hline 15 & 18 & 19 & 21 & 23 & 25 \\
\hline 14 & 15 & 17 & 18 & 22 & 23 \\
\hline 13 & 14 & 15 & 16 & 18 & 21 \\
\hline 10 & 12 & 13 & 14 & 16 & 17 \\
\hline 9 & 10 & 11 & 12 & 13 & 12 \\
\hline 7 & 8 & 9 & 10 & 11 & 10 \\
\hline 5.4 & 6 & 7 & 9.5 & 10 & 8 \\
\hline 4 & 5 & 6 & 8 & 9 & 7 \\
\hline 3 & 3 & 3 & 3.5 & 4 & 5 \\
\hline
\end{tabular}


Int.J.Curr.Microbiol.App.Sci (2016) 5(6): 742-752

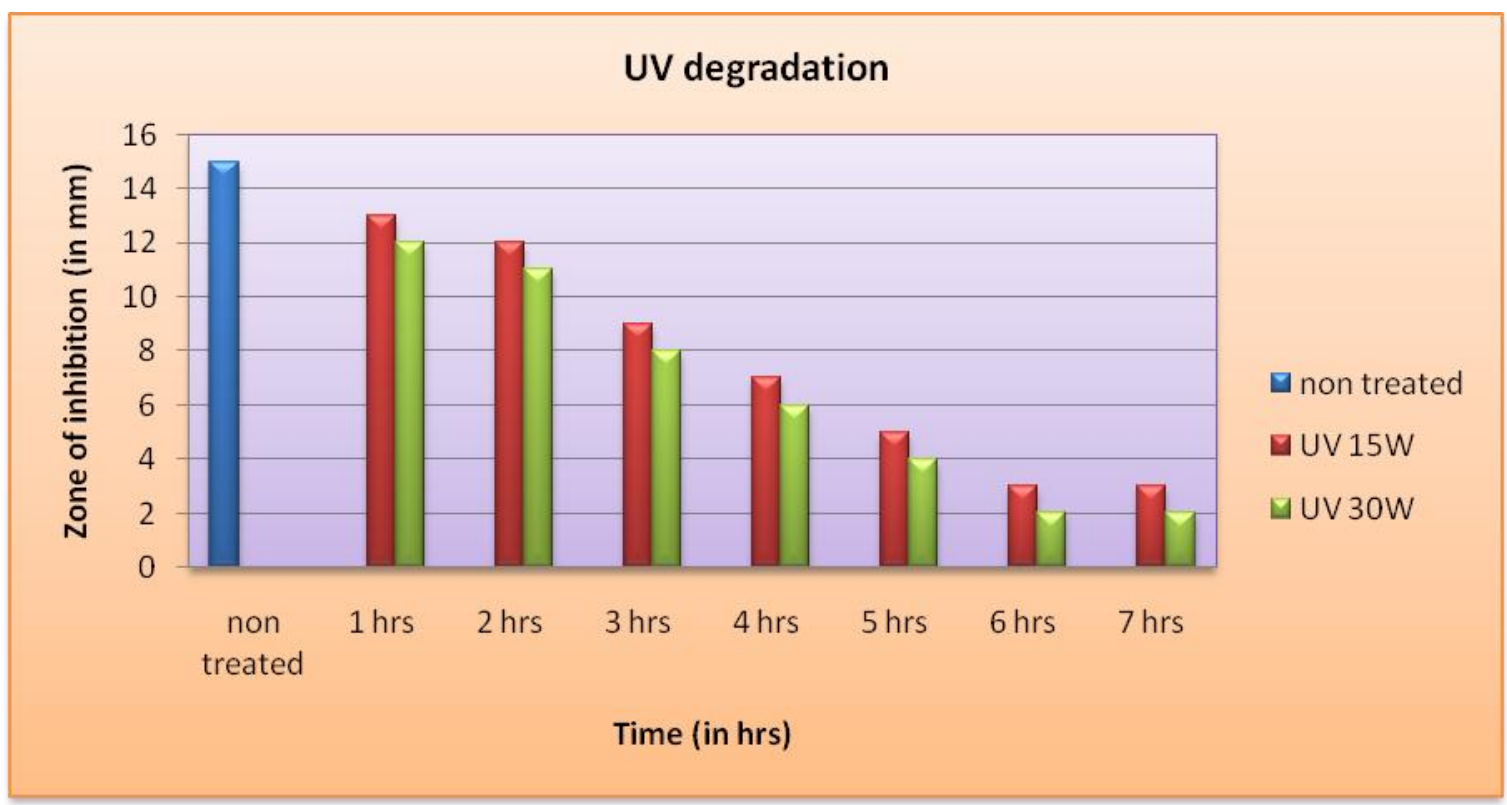

Fig.3 50ppm concentration of ofloxacin showing UV degradation

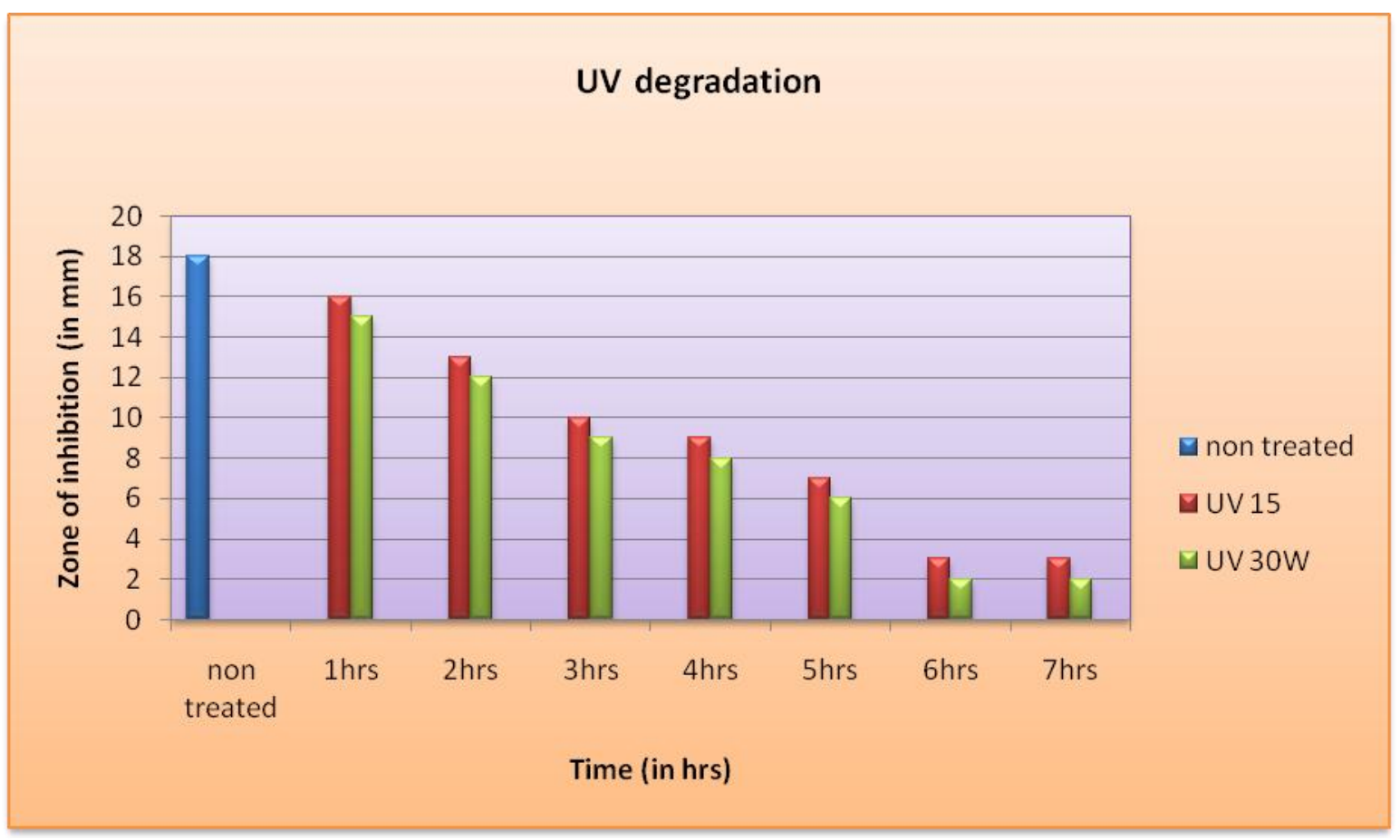

Fig.4 100ppm concentration of Ofloxacin showing UV degradation 
Int.J.Curr.Microbiol.App.Sci (2016) 5(6): 742-752

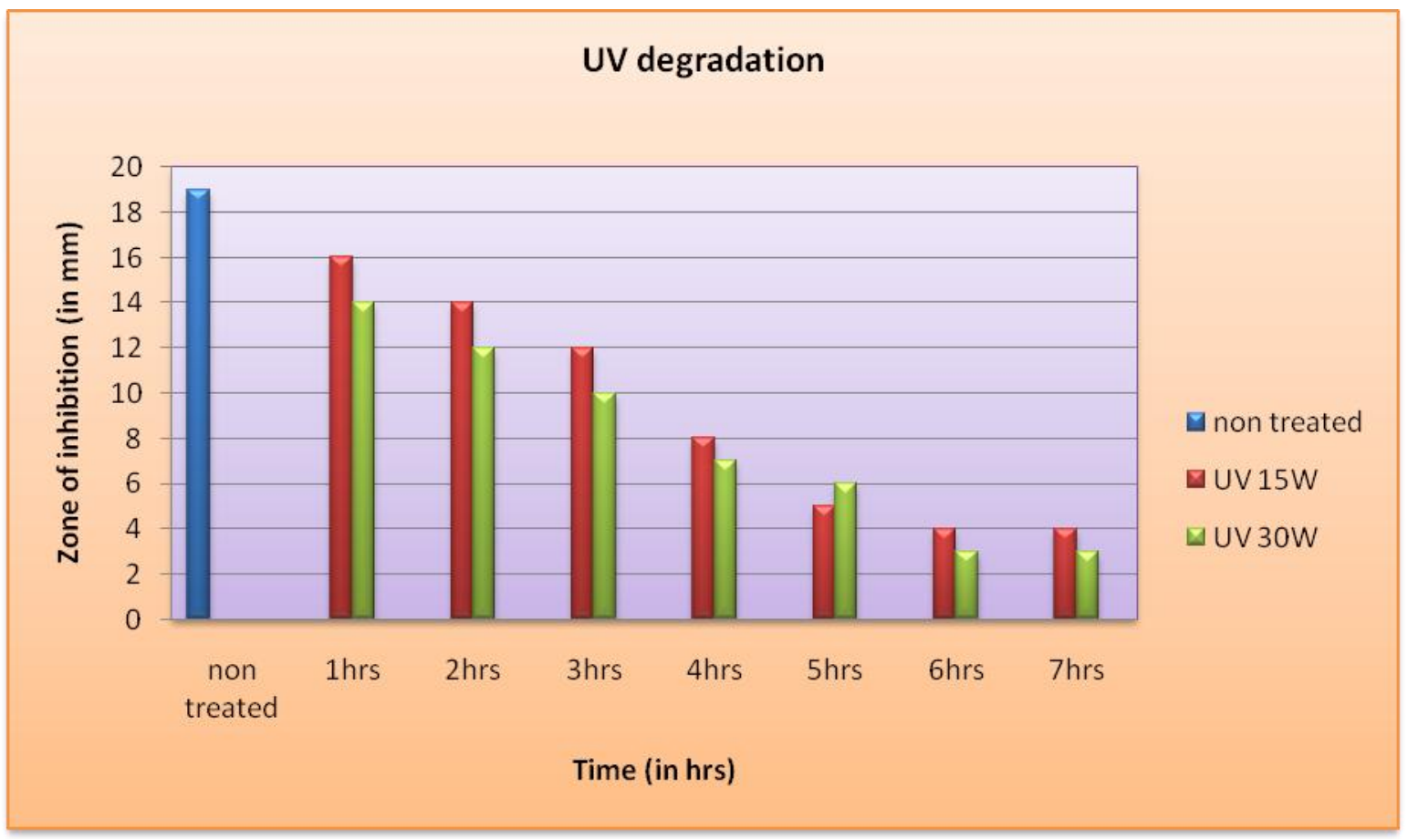

Fig.5 200ppm concentration of Ofloxacin showing UV degradation.

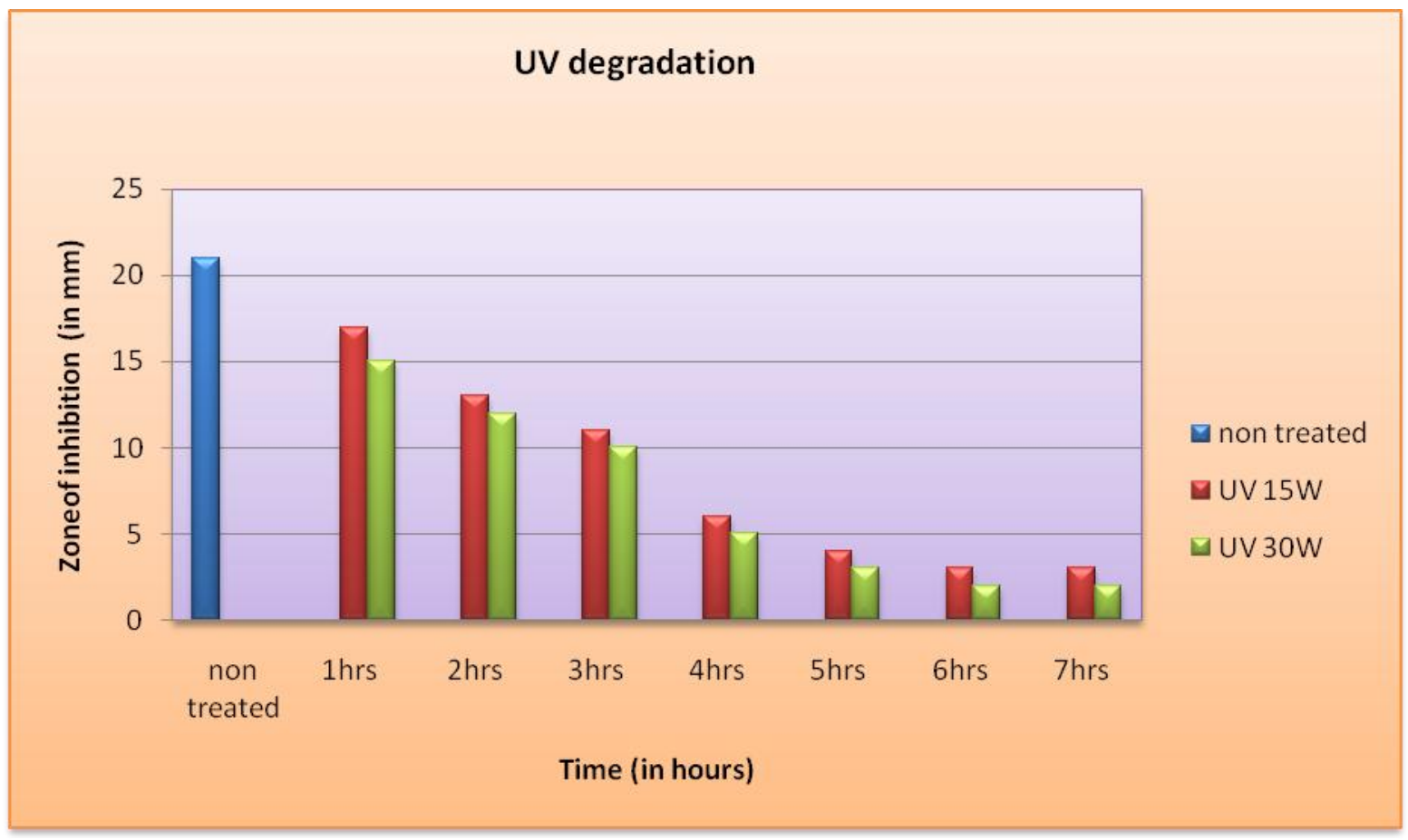

Fig.6 300ppm concentration of Ofloxacin showing UV degradation. 
Int.J.Curr.Microbiol.App.Sci (2016) 5(6): 742-752

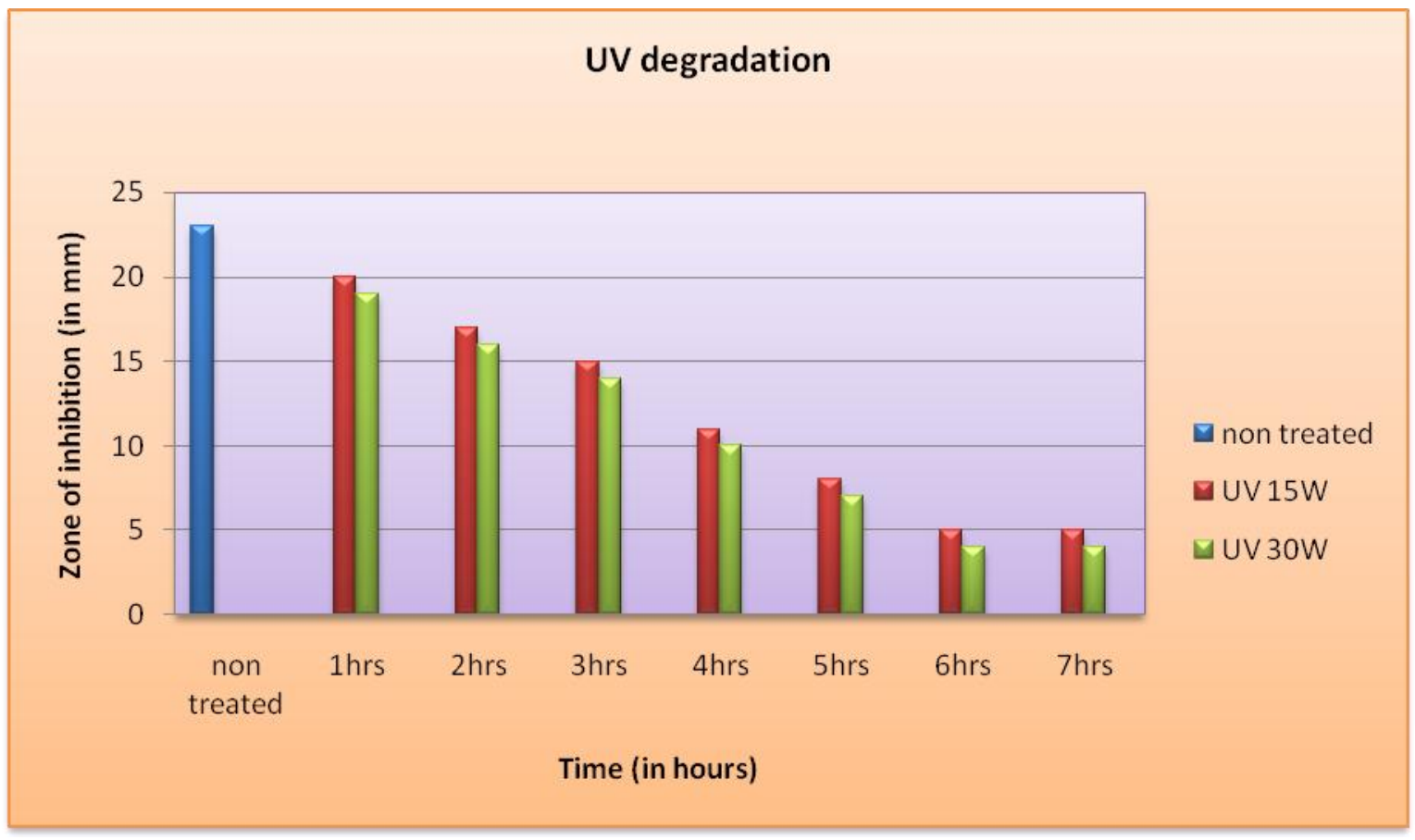

Fig.7 400ppm concentration of Ofloxacin showing UV degradation

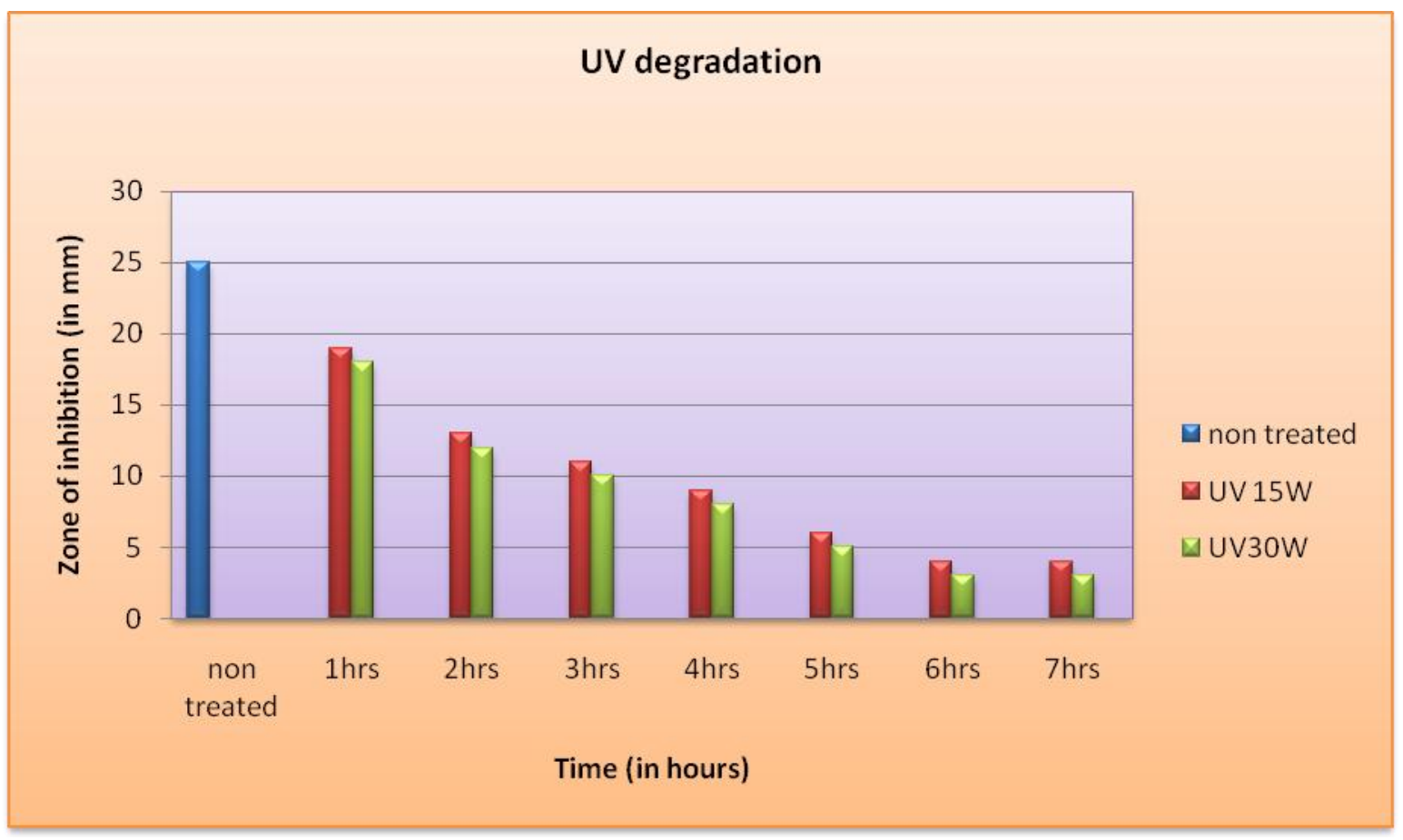

Fig.8 500ppm concentration of ofloxacin showing UV degradation 


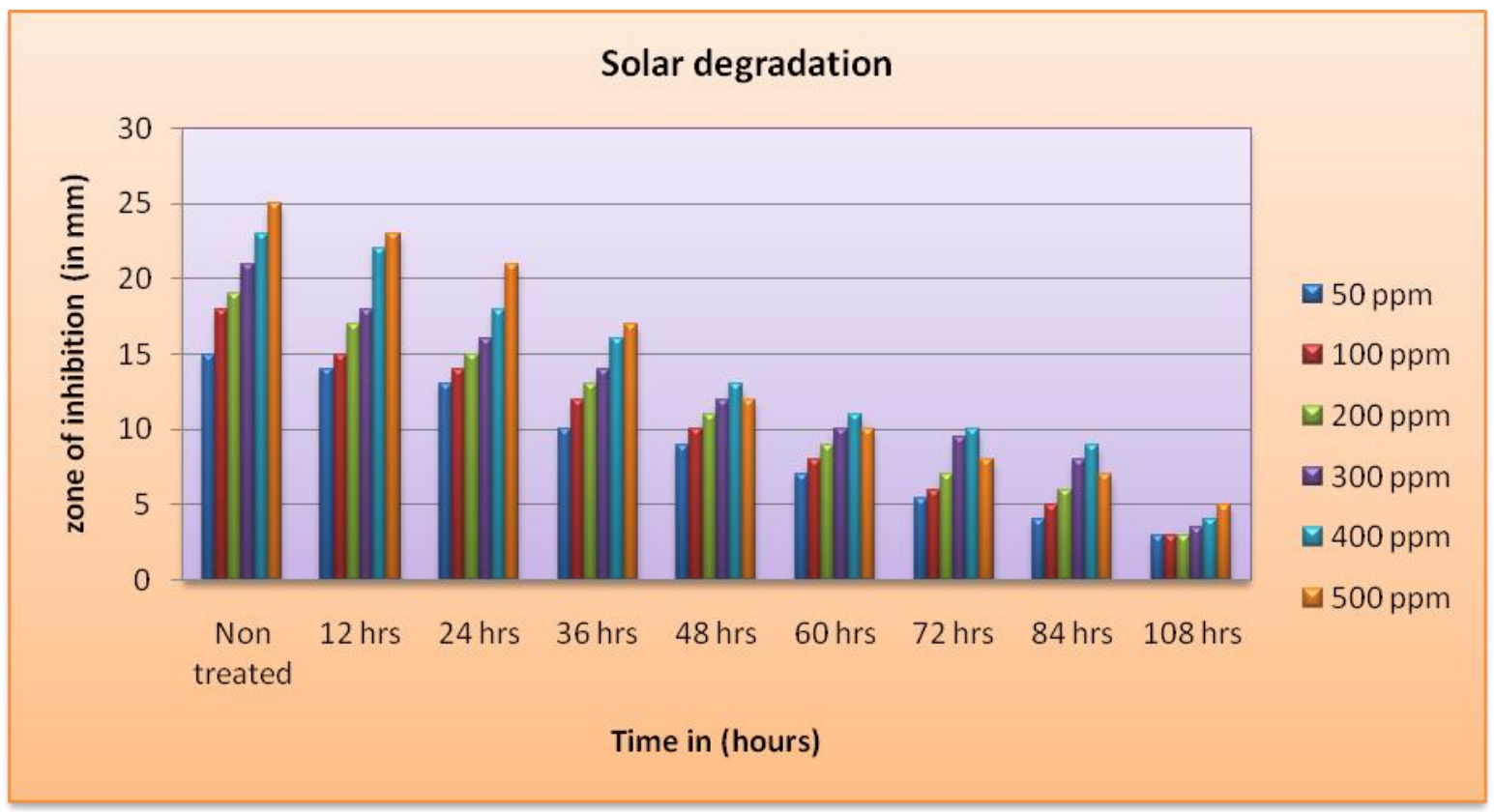

Figure.9 Ofloxacin showing solar degradation.

Bhakta et al., (2009) have studied the photocatalytic degradation of sulphamethoxazole and trimethoprim antibiotics by applying the combined effect of $\mathrm{TiO}_{2}$ and UV. They concluded that the degradation was slower when treated only with UV. They also noticed that degradation rate of sulphamethoxazole was faster to trimethoprim. Ge et al., (2015) have studied the solar and hydroxyl radical oxidation of danofloxacin, ciprofloxacin, levofloxacin, difloxacin and sarafloxacin and enrofloxacin fluoroquinolones antibiotics oxidation in surface water. They also noticed that the rate of fluoroquinolones degradation was maximum after solar exposure than the hydroxyl radical oxidation. Peres et al., (2015) have recorded the degradation of ofloxacin antibiotic with the help of $\mathrm{UV} / \mathrm{TiO}_{2}$ and $\mathrm{UV} / \mathrm{TiO}_{2} / \mathrm{H}_{2} \mathrm{O}_{2}$. They also reported the degradation efficacy of UV/ $\mathrm{TiO}_{2}$ was $89.3 \%$ in 60 minutes for ofloxacin and after addition of $\mathrm{H}_{2} \mathrm{O}_{2}$, the degradation efficacy increased to $97.8 \%$ and the concentration of photocatalyst also increased the degradation efficacy ofloxacin.
In conclusion, the solar and UV degradation of ofloxacin antibiotic was studied. The UV degradation $(15 \mathrm{~W}$ and $30 \mathrm{~W})$ was best after 6 hrs. of the exposure and after this exposure degradation rate was stable. The solar degradation of ofloxacin was at lower rate in comparison to the UV exposure. All the concentration ranging from 50pp to 500ppm of the ofloxacin showed the higher degradation after $108 \mathrm{hrs}$. The authors have recorded the highest solar degradation efficiency at 500ppm. From the above observations it is concluded that the degradation of ofloxacin antibiotic present in the soil, garbage etc. can be possible in the fields also.

\section{References}

BhaktaNathJatindra, Munekage, Yukihiro. 2009. Degradation of Antibiotics (Trimethoprim and Sulphamethoxazole) Pollutants Using UV and $\mathrm{TiO}_{2}$ in Aqueous Medium, Modern Appl. Sci., 3(2).

Burhenne, J., Ludwig, M., Nikoloudis, P., 
Spiteller, M. 1997. Photolytic degradation of fluoroquinolone carboxylic acids in aqueous solution .1. Primary photoproducts and half-lives. Environ. Sci. Pollut. Res., 4: $10-15$.

Chen Dong-hui Wu Yang, KookanaRai. 2011. Aqueous Photodegradation of Selected Antibiotics under Different Conditions.International Conference on Biology, Environ. Chem., 1: 191194.

Ferguson, J., Phillips, G., McEwan, J., Moreland, T., Johnson, B.E., 1988. Loss of antibiotic activity caused by photodegradation: in vivo studies. British J. Dermatol., 119(4): 550-551.

Ge, L., Na, G., Zhang, S., Li, K., Zhang, P., Ren, H., Yao, Z. 2015. New insight into the aquatic photochemistry of fluoroquinolone antibiotics: Direct photodegradation, hydroxyl-radical oxidation, and antibacterial activity changes. Sci. Total Environ., 527528: 12-17.

Hernandez, F., Rivera, A., Ojeda, A., Zayas, T., edillo, L., 2012. Photochemical Degradation of the Ciprofloxacin Antibiotic and Its Microbiological Validation. J. Environ. Sci. Engi., A.1: 448-453.

Hubicka, U., Zmudzki, P., Talik, P., Zuromska, B., Krzek, J. 2013. Photodegradation assessment of ciprofloxacin, moxofloxacin, norfloxacin and ofloxacin in the presence of excipients from tablets by UPLC-MS/MS and DSC. Chem. Central J., 7: 133.

Ichihara, N., Tachizawa, H., Tusumura, M., Vne, T., Sato, K. 1984. Chemother., Tokyo, 32: 118.

Jasim, H.A., Ali, Sabaa, Abdulla, Madher N. 2010. Evaluation of Antibacterial Activity of Tetracycline and
Cephalexine Decomposed by Sunlight, J. Basrah Res.( (Sciences)), Vol. (36): 73-78.

Liu, Feng, Wu, Jinshui, Ying, Guang-gua, Luo, Zhuanx, Feng, Hong. 2012. Changes in functional diversity of soil microbial community with addition of antibiotics sulfamethoxazole and Chlortetracycline. Appl. Microbiol. Biotechnol., 95(6): 1615-1623.

Liu, N., Sijak, S., Zheng, M., Tang, L., Xu, G., Wu, M. 2015. Aquatic photolysis of florfenicol and thiamphenicol under direct UV irradiation, $\mathrm{UV} / \mathrm{H}_{2} \mathrm{O}_{2}$ and $\mathrm{UV} / \mathrm{Fe}(\mathrm{II})$ processes. Chem. Engineering J., 260: 826-834.

Peres, M.S., Maniero, M.G., Guimaraes, J.R. 2015. Photocatalytic degradation of ofloxacin and evaluation of the residual antimicrobial activity. Photochemical and Photobiological Sci., 14(3): 556-62.

Phillips, G., Johnson, B.E. and Ferguson, J., 1990. The loss of antibiotic activity of ciprofloxacin by photodegradation. J. Antimicrob. Chemother., vol 26,pp783-789.

Rege, P.V., Mapari, R. 2011. Simultaneous quantification of ofloxacin and ornidazole from combined pharmaceutical drug formulation by HPLC. Int. J. Pharma and Bio Sci., vol 2(4): 51-58.

Santos, L.V.S., Meireles, A.M., and Lange, L.C. 2015. Degradation of antibiotics norfloxacin by fenton, UV and $\mathrm{UV} / \mathrm{H}_{2} \mathrm{O}_{2}$ J. Environ. Management, 154: 8-12.

Sato, K., Matsura, V. Inone, M. Veno, T. Osada, Y. Ogava, H. Mitshuhashi, M. 1982. Antimicrobial Agents and Chemother., 22: 548.

Sturini, M., Speltini, A., Maraschi, F., Pretali, L., Ferri, E.N., Profumo, A. 2015. Sunlight-induced degradation 
of fluoroquinolones in waste water effluent: Photoproducts identification and toxicity. Chemosphere, 134: 313-318.

Tay, K.S., Madehi, N. 2015. Ozonation of ofloxacin in water: by-products, degradation pathway and ecotoxicity assessment. Sci. Total Environ., 520: 23-31.

Thomashow, L.S., Bonsall, R.F., Weller, D.M. 1997. Antibiotic production by soil and rhizosphere microbes in situ. In: Hurst, C.J., Knudson, G.R., McInerney, M.J., Stetzenbach, L.D., Walter, M.V. (Eds.), Manual of Environmental Microbiology, ASM
Press, Washington, DC, pp. 493-499. Tiefenbacher, E.M., Haen, E., Przybilla, B., Kurz, H. 1994. Photodegradation of some quinolones used as antimicrobial therapeutics. $J$. Pharma. Sci., 83(4): 463-467.

Vasquez, M.I., Hapeshi, E., Fatta-Kassinos, D., Kummerer, K. 2013. Biodegradation potential of ofloxacin and its resulting transformation products during photolytic and photocatalytic treatment. Environ. Sci. Pollution Res., 20: 1302-1309.

\section{How to cite this article:}

Gayatri Devi Singh, K.C. Gupta and Archana Shrivastawa. 2016. UV and Solar Degradation of Ofloxacin Antibiotic. Int.J.Curr.Microbiol.App.Sci. 5(6): 742-752. doi: http://dx.doi.org/10.20546/ijcmas.2016.506.082 